\title{
ULIN-D: Web-Based GIS Supporting New Habits in the Tourism Sector in Bandung City
}

\author{
Kalingga Titon Nur Ihsan ${ }^{\mathrm{a}, \mathrm{b}, *}$, Andhika Dimas Purnomo ${ }^{\mathrm{a}, \mathrm{b}}$, Kirana Sekar Arini ${ }^{\mathrm{a}, \mathrm{b}}$ \\ ${ }^{a}$ Remote Sensing and Geographic Information Science Research Group, Faculty of Earth Sciences and Technology, Institut \\ Teknologi Bandung, Indonesia \\ ${ }^{\mathrm{b}}$ Center for Remote Sensing, Institut Teknologi Bandung, Indonesia \\ *Correspondence: kalinggatitonnurihsan@gmail.com
}

KEY WORDS: Covid-19, Adaptation New Habits, Tourism, Spatial Analysis, WebGIS, Health Protocol

\begin{abstract}
:
Indonesia is one of the countries that has enormous tourism potential where this sector has contributed a total of 229.5 trillion for the country's foreign exchange. However, in the current state of the COVID-19 pandemic, many businesses in the tourism sector have to stop temporarily and result in economic pressure which directly impacts the acceleration of the economic recession in Indonesia. One of the solutions to reduce the impact of economic pressure while reducing the risk of COVID-19 transmission in the tourism sector is the application of health protocols that are directly applied in tourist attractions. To do this a variety of careful preparations are needed. In this case, geospatial information technology can help the community, government, and tourism business managers in implementing health protocols in tourist attractions. Seeing the urgency of implementing health protocols in the tourism sector, we developed the ULIN-D product as a WebGIS platform that is able to visualize, plan, and evaluate the condition of health protocol facilities in various tourist locations. Some of ULIN-D's strategic functions are its ability to provide recommended visitor capacity, display the number of visitors in real-time, and display the number of hand-washing places at tourist attractions based on the profile characteristics of each tourist location. The method used in this research is the combination of various kinds of spatial data and nonspatial data in a dynamic and integrated platform. Tourism location profile information is analyzed in detail to obtain accurate scenario results in establishing a standard health protocol. ULIN-D is expected to be a solution and a reference for how geospatial technology can help improve the quality of policies in the tourism sector for the continuation of the new habits adaption.
\end{abstract}

\section{INTRODUCTION}

\subsection{Backgrounds}

The COVID-19 pandemic is still a hot topic around the world. Starting from its first case at the end of 2019 in Wuhan, until November 2020 the number of COVID-19 worldwide reached 61 million cases, with the death toll reaching 1.4 million deaths (Covid-19 Coronavirus Pandemic, 2020). There have been many regulations implemented by various countries to suppress the spread of COVID-19, such as conducting large-scale community detection tests, applying isolation for infected people, rapid preparation and reaction in handling cases, socialdistancing, to close access in and out of the country. The existence of these regulations certainly hinders various economic activities from many sectors, not least the tourism sector.

The tourism sector is one of the sectors that has a multiplier effect, where it can drive economic activity from other sectors so that the country's revenues will increase (Pettinger, 2019). According to data released by the World Travel and Tourism Council (WTTC), as many as 75 million workers in the tourism sector worldwide are at risk of losing their livelihoods due to the COVID-19 pandemic (Skare, Soriano, \& Porada-Rochon, 2020). In previous pandemic cases, such as SARS and H1N1, the number of tourist arrivals that initially decreased will recover almost immediately after the pandemic is said to be over. However, for the COVID-19 pandemic, it has been predicted that the rapid recovery in the number of tourist arrivals cannot occur.

In Indonesia, the tourism sector is one of the country's sources of income that cannot be seen in the eyes. Indonesia is one of the countries that has enormous tourism potential where the sector has contributed a total of 229.5 trillion for the country's foreign exchange in 2018 (Calculating the Contribution of
Tourism Sector to the Economy of Indonesia, 2020). However, in the current condition of the COVID-19 pandemic, many businesses in the tourism sector have to pause and result in economic pressures that directly impact the acceleration of economic recession in Indonesia.

One solution to reduce the impact of economic pressures while reducing the risk of COVID-19 transmission in the tourism sector is the application of health protocols that are directly applied in tourist attractions. Geographic Information System (GIS) is one example of the application of Geodesy and Geomatics Engineering that can be used to find solutions to this problem by combining various spatial and non-spatial data. In this study, it will be further reviewed related to Web GIS as a monitoring platform for tourist attractions in the application of health protocols with the study area of Bandung City.

\subsection{Formulation of the Problems}

Based on the background that has been explained, it can be derived problem formulation in this study, namely:

1. How to reduce the risk of COVID-19 transmission in the tourism sector?

2. How is WebGIS used in the selection of safe tourist attractions?

3. How to reduce the impact of economic losses on the tourism sector in the event of the COVID-19 pandemic?

\subsection{Purpose}

The purpose of this study is to:

1. Determining the parameters of risk of COVID-19 transmission in the tourism sector in Bandung.

2. Create a WebGIS tourist attraction information provider in The City of Bandung and its vulnerability to the risk of transmission of COVID-19. 


\subsection{Significance of the Study}

The benefits of this research are to:

1. Become a reference for the public when going to travel to Bandung during the COVID-19 pandemic.

2. Assisting the public in implementing health protocols at tourist attractions in The City of Bandung.

3. To be a guideline for the government in making policy decisions related to the tourism sector in the city of Bandung.

\section{MATERIAL AND METHODS}

\subsection{Health Protocol}

Linguistically, protocol can be interpreted as a detailed design related to a procedure, treatment or scientific experiment. Since the COVID-19 pandemic, the term health protocol has become familiar to Indonesians. To enforce health protocols and improve efforts to prevent and control COVID-19 for people in public places and facilities, the Government of Indonesia issued a Decree of the Minister of Health of the Republic of Indonesia Number HK.01.07/MENKES/382/2020 concerning Health Protocols for People in Public Places and Facilities in order to Prevent and Control Corona Virus Disease 2019 (COVID-19). In this document, it says the general principles of health protocols as well as the provisions of health protocols in various public facilities. Some of the public facilities described include markets, shopping centers, inns, restaurants, sports facilities, public transportation modes, airports, salons, creative economy services, houses of worship, event organizing services, as well as tourist attractions.

\subsection{Visitor Capacity}

During the COVID-19 pandemic, WHO and CDC provide a policy to keep a distance of $6 \mathrm{ft}$ or about 2 meters to avoid direct contact with others and prevent the transmission of the COVID19 virus. The guidelines are based on the scenario that the virus is transmitted by droplets or air droplets large or small without taking into account other factors. When a person sneezes or coughs, it will release droplets where if we are too close to the person, then we can inhale them. Droplets droplets are possible to contain Corona virus, so to minimize the risk of contracting from others then $6 \mathrm{ft}$ is a considerable range and out of reach of droplets droplets. The range is based on that when a person is infected with a virus that attacks the respiratory tract such as COVID-19, it will generally produce droplets of 5 microns when coughing, sneezing, or talking. The measure will fall to the ground at a distance of $3 \mathrm{ft}$ to $6 \mathrm{ft}$, and will not hit anyone else who is nearby at a distance of $6 \mathrm{ft}$.

In the implementation to see the capacity of visitors, the policy is used by implementing a safe distance of $6 \mathrm{ft}$. With these policy rules, of course, the capacity of each tourism place will be reduced in order to avoid crowds in a place and prevent the emergence of new clusters in the tourism sector.

\subsection{Spatial Analysis}

Spatial analysis is a set of techniques that can be used in the processing of GIS data. From spatial analysis, it can find and describe the level or pattern of a spatial phenomenon, so that it can be better understood. In relation to GIS, spatial analysis has several functions. The functions of spatial analysis according to Eddy Prahasta (2009), among others:
- Classification(reclassify), which is the difficulty to reclassify a data to become a new spatial data and based on certain criteria or attributes.

- Network, which is a relationship that refers to spatial data points or lines as an inseparable network.

- Overlay, which is the functionality that generates a new layer of spatial data, where the layer is the result of a combination of at least two layers that become inputs.

- Buffering, which is a function that will generate a new spatial layer with polygon shapes and has a certain distance from the spatial elements that become inputs

- 3D Analysisis a function consisting of sub-functions related to the presentation of spatial data contained in a 3dimensi space or a dijital surface.

- Digital ImageProcessing, this functionality assumes value or intensity as a scatter or spatial function.

Spatial analysis can be used in determining areas that match a predetermined criterion. In this case spatial analysis will be very helpful to choose the suitability of a place based on predetermined criteria.

\subsection{Participatory Survey}

Participatory survey methods can be used to collect data at various stages of implementation and to analyze communityrelated issues. Participatory survey methods will make it possible to collect data in an intended community by involving or involving the most complex community in the data retrieval process. In this method the community becomes an important part because the process of retrieving data and the results of existing data will focus on the process of participation of a community. In this paper, survey 123 is used as a tool to conduct participatory surveys. ArcGIS Survey 123 is a form that aims to create, share, and analyze the results of the survey obtained. The results will have attribute data and can be integrated with other spatial data through GIS applications.

\subsection{WebGIS}

WebGIS is a web-based Geographic Information System consisting of several interrelated components. WebGIS is a combination of mapping design, digital maps with geographic analysis, computer programming, and a database interconnected into a single piece of web design and web mapping.

ArcGIS Dashboard allows users to communicate information analytically based on location using intuitive and interactive data visualizations on the same screen. Utilizing arcgis dashboard can help to make decisions, visualize a trend, monitor status in real time and inform and display in one interactive screen.

\subsection{Methods}

The data needed to conduct this research are tourist attractions data, building type data, building area data, tourist attraction operational duration data, COVID-19 related data, population density data, road accessibility data, restaurant and hotel data around tourist attractions, and handwashing data on tourist attractions. Data on tourist attractions, restaurants, and hotels and their attributes are obtained from Open Street Map (OSM) 
data. Data on the operational duration of tourist attractions obtained from tourist websites or Google Maps. Road accessibility data is obtained from the Geospatial Information Agency (BIG). Population density data obtained from the Central Bureau of Statistics (BPS) Bandung. Covid-19-related data is obtained from covid19.bandung.go.id page. Data on handwashing in tourist attractions is obtained from participatory surveys using survey 123 provided by ESRI.

In this research, we conducted a series of data processing processes from the beginning until a WebGIS will be formed. The flow of data processing can be seen in Kesalahan! Sumber referensi tidak ditemukan.

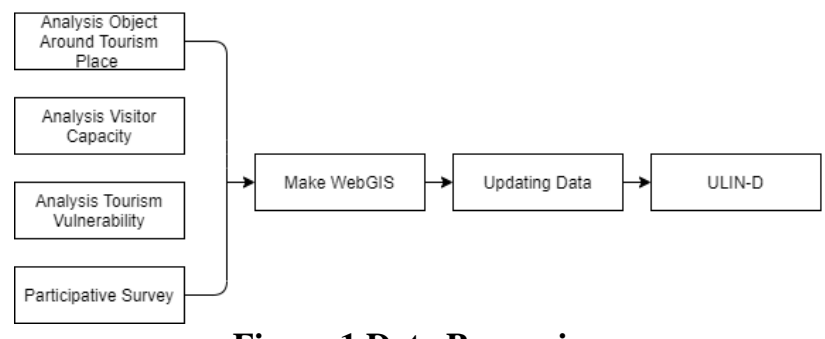

\section{Figure 1 Data Processing}

The determination of supporting facilities was first done by extracting data of facilities located in the bandung area. Supporting data used include restaurant or restaurant data, accommodation data, and MSME data. Then, the process of spatial analysis buffer on the data of tourism places. Buffering is done at a radius of 500 meters, so that the information obtained is not too wide or too narrow coverage. From the result of the buffer is then done intersect process with each supporting data. The result of the intersect is information supporting facilities around the tourist attractions with a radius of 500 meters.

In determining the capacity of visitors to tourist attractions during the COVID-19 pandemic, calculations are used with the $12 \mathrm{ft}$ grid rule. This calculation is based on that the safe distance suggested by the $C D C$ to avoid direct contact with others and avoid crowds and keep it from being easy to contract COVID19 is $6 \mathrm{ft}$, then it is also taken into account that there is an unpredictable and dynamic movement of each person in the tourism venue, so that the $12 \mathrm{ft}$ grid rule is used to minimize the influence of COVID-19 transmission in tourist attractions. Visualizing the distance at tourist attractions can be seen in Kesalahan! Sumber referensi tidak ditemukan.

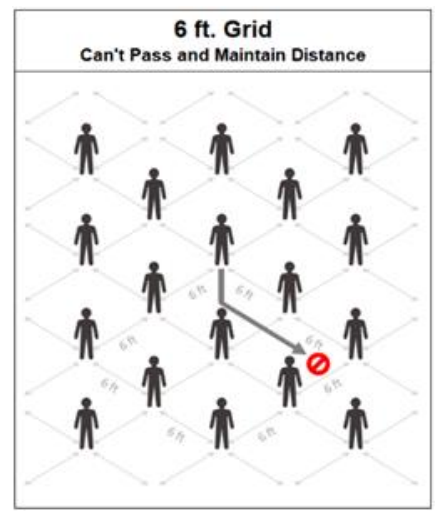

Figure 2 Social Distancing Calculator

Furthermore, the area of each tourist attraction is determined. The broad value is obtained from the extraction of polygon data of each tourist attraction on the OSM web, then the calculation of geometry field on the attributes of the table to get the value of the area of polygons that are assumed to be the area of tourism. However, because the area obtained does not take into account the facilities, facilities, and infrastructure contained in the tourism site, it is then assumed that the most optimal use of the area used in each tourism sector is 50 percent of the total area.

Calculation of the amount of capacity at each tourism place with the rules of keeping distance to follow the optimum distance avoided transmission is used the following equations.

\section{Capacity $=$ Area $\times(1-($ percent of floor space 100$)) /$} 144

In determining the insecurity of tourist attractions used spatial analysis techniques and weighting to find out which areas have great potential for the transmission of Covid-19. In determining the vulnerability of tourist attractions used several parameters, namely tourism buildings, covid-19 data in Bandung, population, and accessibility. After scoring, the next stage is to classify the vulnerability area of covid-19 transmission. The vulnerability classes used in this study were 4 classes with the classification of covid-19 incurable zones, low risk zones, medium risk zones and high risk zones. The range of each class can be found in Kesalahan! Sumber referensi tidak ditemukan.

\begin{tabular}{|c|c|}
\hline Class & Hose \\
\hline No Impact Zone & $0,521-0,963$ \\
\hline Low Risk Zone & $0,963-1,405$ \\
\hline Medium Risk Zone & $1,405-1,846$ \\
\hline High Risk Zone & $1,846-2,29$ \\
\hline \multicolumn{2}{|c|}{ Table 1 Classification of Zone }
\end{tabular}

Participatory surveys aim to engage and engage a community to collect data. In the process, this survey will be conducted to obtain data that is difficult to access or data that only takes the form of statistical values without knowing the spatial distribution, such as the distribution data of handwashing places that are still functioning or not. In addition, participatory surveys integrated with GIS applications will be able to know the real situation in the field quickly and make it easier to analyze the data obtained. For example, in the survey of reporting violations of health protocols in tourism places that allows to know the incident of violations quickly from public reporting and immediately possible to follow up the reporting conducted.

In this paper, participatory survey methods will be utilized to obtain data related to handwashing and data reporting violations of health protocols in tourist attractions. Surveys will be conducted by forming an online form utilizing the ArcGIS Survey123application. The form will be accessible at any time and can be filled in by everyone. Then the survey results obtained will be contained in a layer that can be visualized in the form of spatial distribution and can be used to conduct further analysis process.

\section{RESULT AND DISCUSSION}

\subsection{WebGIS ULIN-D}

Webgis ULIN-D Bandung for the general public can be accessed using the link https://garuk.in/ULINDBandung . The general user version of WebGIS ULIN-D can be seen in the image below. 


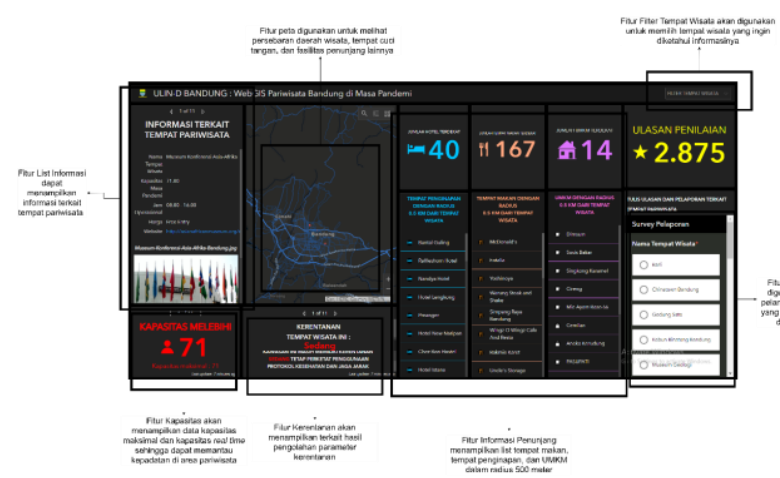

3.2 WebGIS ULIN-D Admin

ULIN-D Bandung Admin is used by the manager to inform the number of real time visitors. In addition, in WebGIS ULIN-D admins are connected with complaint surveys, so that problems that arise can be resolved immediately. WebGIS ULIN-D Admin can be accessed via the https://garuk.in/ULINDBandungAdmin link. The ULIN-D Admin WebGIS display can be seen in the image below.

\section{CONCLUSION}

A map of the vulnerability of COVID-19 transmission has been created at bandung tourist attractions. Produced tourist attractions in the city of Bandung has a low risk and medium risk. WebGIS 'ULIN-D' has been created to provide information on tourist attractions in Bandung and its vulnerability to the risk of COVID-19 transmission. In the improvement for users can later be made improvements to the appearance of webGIS for the version on the mobile phone. Can be done adding more tourist attractions because at the moment we are still just sampling some tourist attractions. ULIN-D coverage can be developed to outside the city of Bandung. It can also be further developed related to the integration of spatial and non-spatial data to increase the usability of ULIN-D.

\section{ACKNOWLEDGEMENTS}

The authors are grateful to acknowledge the support from Earth Research Collaboration Program by Faculty of Earth Sciences and Technology, Institut Teknologi Bandung. We also thank the anonymous reviewers whose valuable comments greatly helped us to prepare an improved and clearer version of this paper. All persons and institutes who kindly made their data available for this analysis are acknowledged.

\section{REFERENCES}

Ari, Y. (2020). MAPPING THE SPREAD, POTENTIAL AND VULNERABILITY OF THE COVID-19 PANDEMIC IN LEMBANG DISTRICT, WEST BANDUNG REGENCY.

Covid-19 Coronavirus Pandemic. (2020, November 27). From Worldometer: https://www.worldometers.info/coronavirus/?

Hermawan, A., Awaluddin, M., \& Darmo, B. (2017). CREATION OF TOURISM INFORMATION WEBGIS APPLICATION AND SUPPORTING FACILITIES IN KUDUS REGENCY. Undip Journal. Calculating the Contribution of Tourism Sector to the Economy of Indonesia. (2020, February 26). From CNN Indonesia:

https://www.cnnindonesia.com/ekonomi/20200226121314-532478265/calculate-contribution-sector-tourism-share-economy-ri
Pettinger, T. (2019, November 2). The Multiplier Effect. From Economics Help: https://www.economicshelp.org/blog/1948/economics/themultiplier-effect/

Sholahuddin, M. (n.d.). SIG TO MAP FLOOD AREAS BY SCORING AND WEIGHTING METHODS (DISTRICT CASE STUDY JEPARA).

Skare, M., Soriano, D. R., \& Porada-Rochon, M. (2020). Impact of COVID-19 on the travel and tourism industry. Technological Forecasting \& Social Change.

Covid 2020 Expert Team. (2020). Towards the Productive and Safe Stages of Indonesia. 